\title{
Adenanthin targets peroxiredoxin I/II to kill hepatocellular carcinoma cells
}

\author{
J-K Hou', Y Huang ${ }^{*, 2}$, W He², Z-W Yan², L Fan², M-H Liu'², W-L Xiao ${ }^{3}$, H-D Sun ${ }^{*, 3}$ and G-Q Chen ${ }^{*, 1,2,4}$
}

Adenanthin, a natural diterpenoid isolated from the leaves of Isodon adenanthus, has recently been reported to induce leukemic cell differentiation by targeting peroxiredoxins (Prx) I and II. On the other hand, increasing lines of evidence propose that these Prx proteins would become potential targets to screen drugs for the prevention and treatment of solid tumors. Therefore, it is of significance to explore the potential activities of adenanthin on solid tumor cells. Here, we demonstrate that Prx I protein is essential for the survival of hepatocellular carcinoma (HCC) cells, and adenanthin can kill these malignant liver cells in vitro and xenografts. We also show that the cell death-inducing activity of adenanthin on HCC cells is mediated by the increased reactive oxygen species (ROS) levels. Furthermore, the silencing of Prx I or Prx II significantly enhances the cytotoxic activity of adenanthin on HCC, whereas the ectopic expression of Prx I and Prx II but not their mutants of adenanthin-bound cysteines can rescue adenanthin-induced cytotoxicity in Prxs-silenced HCC cells. Taken together, our results propose that adenanthin targets Prx I/II to kill HCC cells and its therapeutic significance warrants to be further explored in HCC patients.

Cell Death and Disease (2014) 5, e1400; doi:10.1038/cddis.2014.345; published online 4 September 2014

Peroxiredoxins (Prxs) belong to an important superfamily of small nonseleno peroxidases that scavenge hydrogen peroxide $\left(\mathrm{H}_{2} \mathrm{O}_{2}\right)$ and organic hydroperoxide, and are essential for maintaining reactive oxygen species (ROS) homeostasis in the cells. ${ }^{1}$ On the basis of the numbers of conserved cysteine (Cys) residues participating in the redox reaction, Prxs are divided into the typical 2-Cys Prxs (including Prx I-IV), atypical 2-Cys Prx (Prx V) and 1-Cys (Prx VI). ${ }^{2}$ The typical Prxs form homodimers through an intersubunit disulfide bond, whereas the atypical Prx $\mathrm{V}$ forms a monomer with intramolecular disulfide bond during $\mathrm{H}_{2} \mathrm{O}_{2}$ catalysis. Besides their cytoprotective function against oxidative stress, Prxs also contribute to the regulation of $\mathrm{H}_{2} \mathrm{O}_{2}$ signaling in cellular responses to stimulators such as growth factors and tumor necrosis factors. ${ }^{2-5}$ Emerging evidence has implicated that the aberrant expression of 2-Cys Prx isoform proteins are correlated with several human diseases including cancers, and the elevated Prx expressions are discovered in various cancer tissues, which is possibly due to the adaptive response to oxidative stress facilitating cancer cell growth. ${ }^{6,7}$ On the other hand, knockout of Prx I gene causes spontaneous tumor formation in aging mice, proposing that Prx I can also function as tumor suppressor. Further, it has been shown that Prx I interacts with c-Myc and PTEN, thereby inhibiting c-Myc transcriptional activity and protecting PTEN, respectively, from oxidation-induced inactivation. ${ }^{8-10}$ Moreover, modulated expression of Prxs with small interfering RNA (siRNA) or transfection can potentiate or attenuate, respectively, the sensitivity of radiotherapy and chemotherapy linked with clinical outcomes and overall patient survival. ${ }^{11}$ These studies suggest that Prxs would be potential therapeutic targets for cancer prevention and treatment. ${ }^{12}$

Hepatocellular carcinoma $(\mathrm{HCC})$ is the third leading cause of cancer mortality and the fifth most common cancer worldwide. ${ }^{13} \mathrm{HCC}$ is often diagnosed at an advanced stage so that patients lose the opportunity of surgical resection. ${ }^{14,15}$ There has been an explosion in our understanding of the pathophysiology and molecular alterations occurring in HCC and a series of molecular biomarkers that have potential prognostic significance and may be therapeutic targets have been identified over the past decades. ${ }^{16-19}$ However, sorafenib is regarded as the only effective agent available in clinic for these kinds of patients, but it is not completely satisfactory in HCC patients with extrahepatic spread or macrovascular invasion. ${ }^{20}$ Thus, other effective agents need to be further explored.

Previously, our group reported that adenanthin, a diterpenoid isolated from the leaves of Isodon adenanthus, directly targets Prx I and Prx II and inhibits their peroxidase activities, resulting in differentiation induction of acute myeloid leukemia

\footnotetext{
${ }^{1}$ Institute of Health Sciences, Shanghai Institutes for Biological Sciences (SIBS), University of Chinese Academy of Sciences, Chinese Academy of Sciences (CAS) \& Shanghai Jiao Tong University School of Medicine (SJTU-SM), Shanghai, China; ${ }^{2}$ Department of Pathophysiology, Key Laboratory of Cell Differentiation and Apoptosis of Chinese Ministry of Education, SJTU-SM, Shanghai, China; ${ }^{3}$ State Key Laboratory of Phytochemistry and Plant Resources in West China, Kunming Institute of Botany, Chinese Academy of Sciences, Yunnan, China and ${ }^{4}$ State Key Laboratory of Oncogenes and Related Genes, Shanghai Cancer Institute, SJTU-SM, Shanghai, 200032, China

${ }^{*}$ Corresponding author: G-Q Chen and Y Huang, Department of Pathophysiology, Shanghai Jiaotong University School of Medicine, 280, Chong-qing South Road, Shanghai, 200025, China. Tel/Fax: + 8621 64154900; E-mail: chengq@ shsmu.edu.cn or huangying@ @shsmu.edu.cn

or H-D Sun, Kunming Institute of Botany, Chinese Academy of Sciences, 132 Lanhei Road, Heilongtan, Kunming 650201, Yunnan, China. Tel: +8687165223251 ; Fax: +86 871 65216343; E-mail: hdsun@mail.kib.ac.cn

Abbreviations: DCFDA, dichlorodihydrofluorescein diacetate; $\mathrm{HCC}$, hepatocellular carcinoma; $\mathrm{H}_{2} \mathrm{O}_{2}$, hydrogen peroxide; IC50, half maximal inhibitory concentration; NAC, N-acetyl---cysteine; PARP, poly-(adenosine diphosphate ribose) polymerase; Prxs, peroxiredoxins; ROS, reactive oxygen species; TUNEL, terminal deoxynucleotidyl transferase (TdT)-mediated dUTP nick end labeling; siRNA, small interfering RNA; WT, wild type

Received 27.1.14; revised 1.6.14; accepted 10.7.14; Edited by Y Shi
} 
cells. $^{21,22}$ In this work, we investigated the effect of adenanthin on HCC cells, and find that the natural agent can kill malignant liver cells in vitro and xenografts through targeting Prx I and Prx II and thus increasing ROS level. These findings validate that Prx I/II are the effective drug targets for killing cancer cells and that therapeutic significance of adenanthin warrants to be further explored in HCC patients.

\section{Results}

Adenanthin effectively kills malignant liver cells. We first detected the possible effect of adenanthin on the growth of three human HCC cells (SMMC-7721, Bel-7402 and HepG2) and two human immortal hepatic cell lines (QSG-7701 and HL7702). For this purpose, these cells were exposed into different concentrations of adenanthin for 24 or $48 \mathrm{~h}$, followed by cell counting kit 8 (CCK-8) assay. The results showed that all three HCC cell lines, especially HepG2 cells, were more sensitive to adenanthin-induced growth inhibition. IC50s were 4.97, 8.45 and $10.75 \mu \mathrm{M}$ during the $24 \mathrm{~h}$ treatment, and 2.31, 6.67 and $8.13 \mu \mathrm{M}$ during the $48 \mathrm{~h}$ treatment, respectively, for HepG2, Bel-7402 and SMMC-7721 cells (Figure 1a). Notably, two human immortal hepatic cell lines were adenanthin-insensitive relatively to HCC cells, with IC50 values of 27.34 and $27.33 \mu \mathrm{M}$ (24h treatment) and 19.58 and $20.41 \mu \mathrm{M}$ (48 h treatment), respectively, for QSG-7701 and HL-7702 cells.

We then carried out the terminal deoxynucleotidyl transferase-mediated dUTP nick end labeling (TUNEL) assay to assess the cell death with VP16 treatment as controls. As depicted in Figure 1b, VP16 similarly induced all five cell lines to undergo cell death in a dose-dependent manner. Thus, $50 \mu \mathrm{M}$ of VP16 was used as a positive control in the following experiments for cell death assay. Under light microscope, less living cells were seen in HepG2 cells under treatment of adenanthin at $3 \mu \mathrm{M}$ and SMMC-7721 and Bel-7402 cells under adenanthin at $9 \mu \mathrm{M}$ for $48 \mathrm{~h}$ (data not shown). Therefore, we used 3 and $9 \mu \mathrm{M}$ of adenanthin to, respectively, treat HepG2 and other four cells for 24 and $48 \mathrm{~h}$, followed by TUNEL assay. The results showed that adenanthin for 24 or $48 \mathrm{~h}$ induced death of three HCC cell more sensitively than those in two immortal hepatic cell lines (Figure 1c). In line with this notion, adenanthin induced caspase-3 activation with the cleavage of its substrate poly-(adenosine diphosphate ribose) polymerase (PARP) in HCC cells in concentration- and time-dependent manners, which was not found in QSG-7701 and HL-7702 cells (Figures 1d and 1e). Collectively, these results suggest that adenanthin more effectively kills malignant liver cells.

ROS mediates adenanthin-induced cell death of HCC cells. It is believed that adaptation to the enhanced cellular stress (such as oxidative stress) is required for cancer cells to survive, and consequently, cancer cells may become addicted to non-oncogenes that do not ordinarily perform such a vital function in normal cells. ${ }^{23,24}$ To address whether the oxidative stress contributes to responses of HCC and human immortal hepatic cells to adenanthin, all five liver cell a
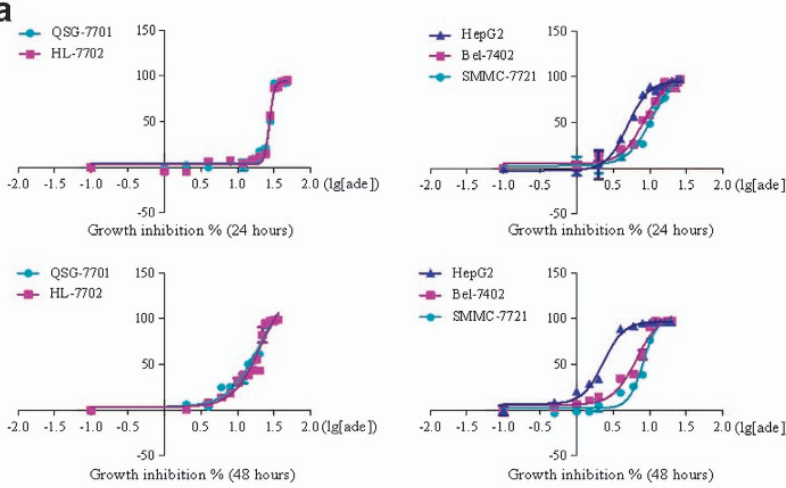

b

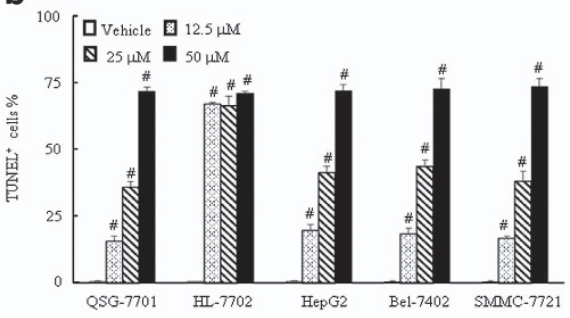

C

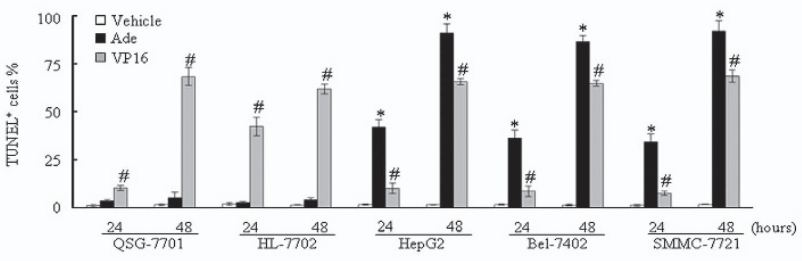

d

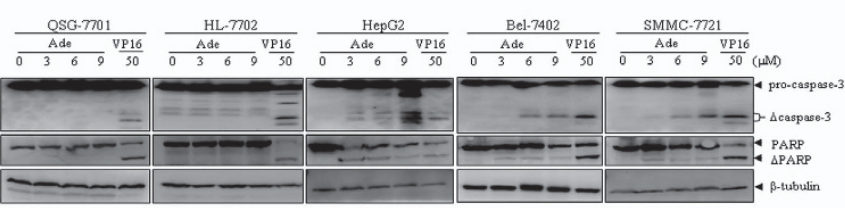

e

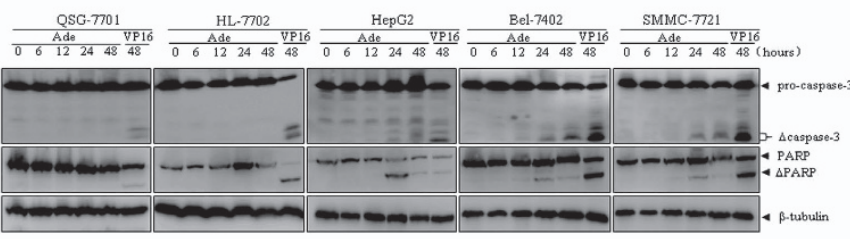

Figure 1 Adenanthin kills HCC cells more effectively. (a) Human immortal hepatic cells (QSG-7701, HL-7702) and HCC cells (SMMC-7721, Bel-7402 and HepG2) were, respectively, treated with and without different concentrations of adenanthin for 24 (top) or $48 \mathrm{~h}$ (bottom). Cell growth was assessed by CCK-8 assay and IC50 values of adenanthin were calculated by Graph Prism 5 software. (b, c) These liver cells were treated with the indicated concentrations of VP16 for $48 \mathrm{~h}$ (b) or HepG2 cells were treated with $3 \mu \mathrm{M}$ adenanthin and other cells were treated with $9 \mu \mathrm{M}$ adenanthin for hours as indicated, together with $50 \mu \mathrm{M}$ VP16 treatment as a control (c), followed by TUNEL assay. TUNEL-positive cells $\%$ were calculated in triplicate samples by observing five random fields in an independent experiment. The data indicate the means with bar as S.D. of triplicate samples in an independent experiment. The symbols ${ }^{*}$ and \# indicate $P<0.01$ compared with the vehicle-treated cells. (d, e) Cells were treated with the indicated concentrations of adenanthin or VP16 for $48 \mathrm{~h}$ (d) or HepG2 cells were treated with $3 \mu \mathrm{M}$ adenanthin and other cells were treated with $9 \mu \mathrm{M}$ adenanthin for hours as indicated (e), followed by western blots for the indicated proteins. All experiments were repeated three times with the same results 
lines were treated with adenanthin at $3 \mu \mathrm{M}$ (for HepG2) or $9 \mu \mathrm{M}$ (for other cells) for $1 \mathrm{~h}$, followed by incubation with fluorophore dichlorodihydrofluorescein diacetate (DCFDA), a dye to monitor intracellular ROS, for $30 \mathrm{~min}$. As consistent with the previous reports, ${ }^{25}$ all three HCC cells displayed higher basal ROS levels than QSG-7701 and HL-7702 cells, as assessed by the fluorescent signal intensity on flow cytometry (Figures $2 \mathrm{a}$ and b). More intriguingly, adenanthin significantly increased ROS production in all three HCC cells rather than two human immortal hepatic cell lines tested (Figures $2 \mathrm{a}$ and b). We also applied DCP-Bio1, a probe to detect cysteine sulfenic acid of oxidative proteins and therefore the oxidative modification of proteins in the cellular context, $^{26}$ into cell lysates from HL-7702 and SMMC-7721 with and without adenanthin treatment. Western blot analysis showed that adenanthin-treated SMMC-7721 but not HL-7702 cells contained significantly increased protein oxidization signaling compared with vehicle-treated control cells (Figure $2 \mathrm{c}$ ), suggesting the increased ROS stress in HCC cells by adenanthin.

To address whether increased ROS production mediates killing of adenanthin to cancer cells, these cells were pretreated by a general ROS scavenger $\mathrm{N}$-acetyl-I-cysteine (NAC). Although NAC treatment did not substantially lower the basal ROS level of HCC cells, as reported, ${ }^{27}$ it did effectively inhibit adenanthin-induced ROS accumulation and protein oxidization in all three $\mathrm{HCC}$ cells (Figures $2 \mathrm{a}-\mathrm{c}$ ). Accordingly, NAC pretreatment could completely abrogate adenanthin-induced cell death of three HCC cells, as determined by morphologic observations, TUNEL assay and caspase-3 activation/PARP cleavage (Figures 2d-f). Considering the possibility that NAC likely protects cells by a direct chemical reaction with adenanthin in analogy to the proposed mechanism for adenanthin's actions, that is, covalent reaction with cysteine 173 of $\operatorname{Prx~I,}{ }^{21}$ we also pre-treated three HCC cells with two additional thiol antioxidants including glutathione and dithiothrietol and two non-thiol antioxidants, vitamin $\mathrm{E}$ analog tiron (sodium 4,5-dihydroxybenzene-1,3disulfonate $)^{28}$ and a superoxide dismutase mimetic tempol. ${ }^{29}$ The results demonstrated that like NAC, all other four antioxidants could significantly inhibit adenanthin-induced ROS production and cell death (Figure $2 \mathrm{~g}$ ). These data suggest that increased ROS is critical for adenanthin-induced death of HCC cells.

Prx I is required for HCC cell survival. Previously, we reported that adenanthin targets Prx I and Prx II, and inhibit their peroxidase activities, resulting in ROS accumulation of leukemic cells. ${ }^{21,22}$ More recently, Muchowicz et al. ${ }^{30}$ also reported that adenanthin can bind with intracellular Prx I and Prx II. On the basis of this notion, we used siRNA specifically against Prx I (designated siPrx I\#1) to knock Prx I down in HCC and immortal hepatic cell lines. Our preliminary experiments showed that, on 6-8 days after transfection of siPrx I\#1, all HCC cells underwent death. Thus, we further transfected with GFP-tagged siPrx I\#1 and a non-specific siRNA as a negative control (NC) into HCC and immortal hepatic cell lines for $48 \mathrm{~h}$. Then, GFP-positive cells were sorted. As depicted in Figure $3 \mathrm{a}$, siPrx I\#1 but not NC completely eliminated the endogenous Prx I but not Prx II protein expression in all five cell lines. HCC cells but not immortal hepatic cells underwent cell death on the sixth day after sorting (Figure 3b). These results suggest that Prx I is essential for the survival of HCC cells.

We further transfected another pair of siRNAs specifically against Prx I (designated siPrx I\#2) and one pair of siRNAs against Prx II (siPrx II) together with a NC siRNA into two human immortal hepatic cell lines. As depicted in Figure 3c, siPrx I\#2 partially silenced Prx I rather than Prx II expression. Vice versa, siPrx II suppressed Prx II but not Prx I expression, proposing the specificity of these siRNAs against Prx I and Prx II. As expected, the silencing of Prx I or Prx II did not accumulate ROS in these cells in the presence or absence of adenanthin (Figure 3d). Accordingly, they also failed to trigger these cells to undergo death, as evidenced by CCK-8 assay (Figure 3e), TUNEL assay (Figure 3f) and caspase-3 activation (data not shown). All these data support that Prx I and Prx II are not essential for survival of these immortal hepatic cell lines.

Prx I/II suppression significantly enhances adenanthininduced HCC cell death. On the other hand, siPrx I\#2 expression partially knocked down Prx I whereas siPrx II remarkably silenced Prx II expression in HCC cells tested (Figure 4a). These siRNAs' expressions did not significantly affect the growth and viability of these HCC cells. We also tried to establish double silencing of Prx I and Prx II in HCC cells, but we found that double depletion of Prx I and Prx II could trigger cell death so as that a stable Prx I/II doubledeleted cell line could not be established, which was similar to the effect of complete elimination of Prx I. The results support that there is compensation between Prx I and Prx II for survival of HCC cells. Therefore, we only assessed the effects of adenanthin on two HCC cells (SMMC-7721 and Bel-7402) with the stable expression of siPrx I\#2 or siPrx II alone. Compared with NC-transfected cells, partial suppression of Prx I increased intracellular ROS accumulation in HCC cells to a degree but with statistical significance and remarkably potentiated adenanthin-induced ROS accumulation in HCC cells (Figure 4b). In line with the notion, partial suppression of Prx I significantly enhanced cytotoxic effects of adenanthin on SMMC-7721 and Bel-7402 cells, as assessed by CCK8 (Figure 4c), caspase-3 activation/PARP cleavage (Figure 4d) and TUNEL assays (Figure 4e). Likewise, the significant suppression of Prx II by siPrx II also enhanced $9 \mu \mathrm{M}$ adenanthin-induced ROS accumulation and cell death in HCC cells (Figures $4 b-d$ and f). Totally, the decreased Prx I or Prx II expression increases the sensitivity of HCC cells to adenanthin.

Re-introduction of Prx I/II abrogates the activity of adenanthin on Prxs-silenced HCC cells. To further validate the role of Prx I and Prx II in adenanthin-induced $\mathrm{HCC}$ cell death, we infected lentiviruses carrying Flag-tagged and siRNA-resistant wild type (WT) Prx I or Prx II and their mutants with adenanthin-targeted cysteines (C173S-Prx I and C172S-Prx II), ${ }^{21}$ together with the empty vector as control, into SMMC-7721 and Bel-7402 cells in the presence of Prx I and Prx II knockdown, respectively, by siPrx I\#2 and siPrx II, as shown in Figure 4a. The expression of 
Flag-tagged WT-Prx I/II and C173S-Prx I or C172S-Prx II were confirmed by western blot (Figures $5 a$ and $b$ ). These cells were, respectively, treated with and without adenanthin at indicated concentrations for $24(5 c, e)$ or $18(5 d, f) h$. The results showed that re-expression of WT-Prx I but not C173S-Prx I could abrogate adenanthin-induced cell death

a
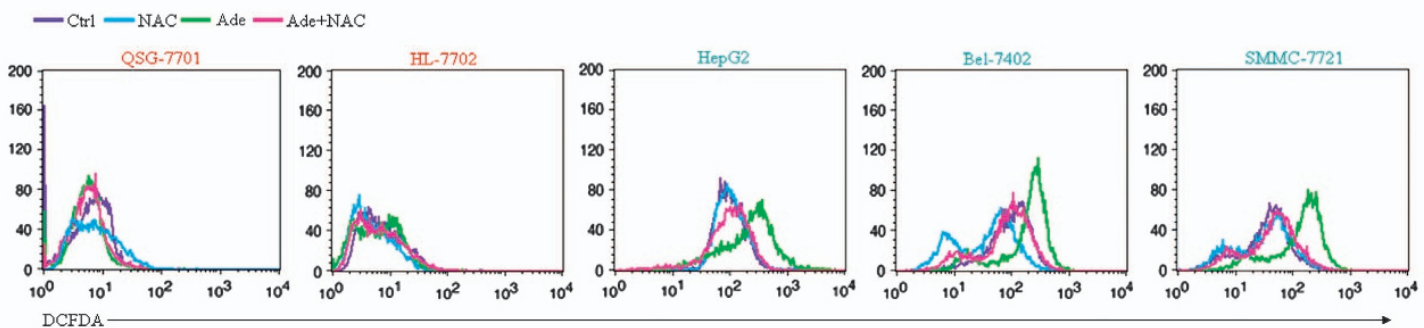

b

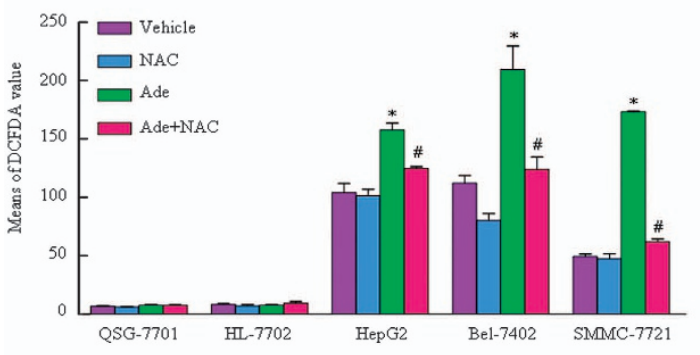

d

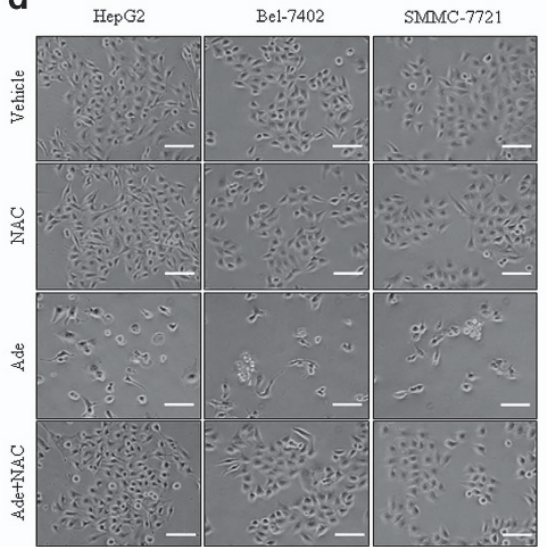

g

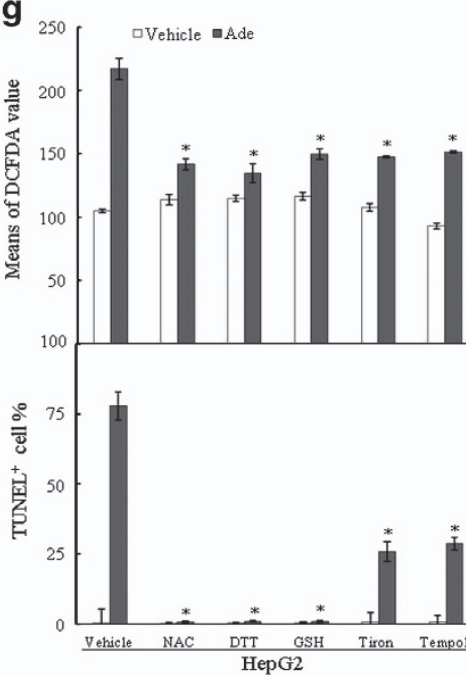

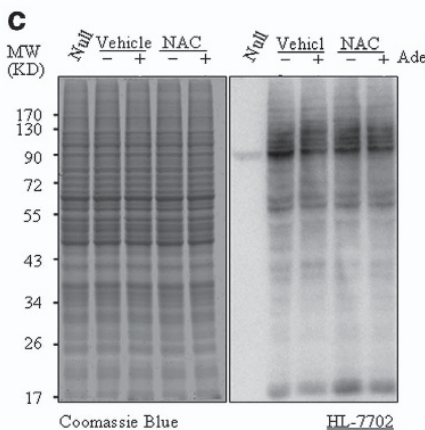

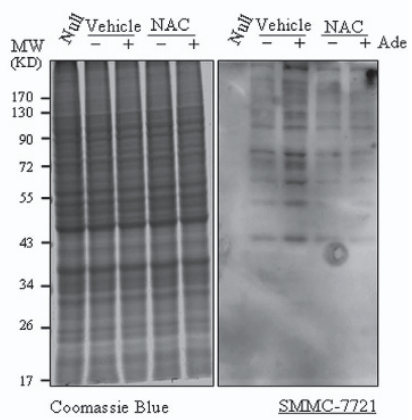

e

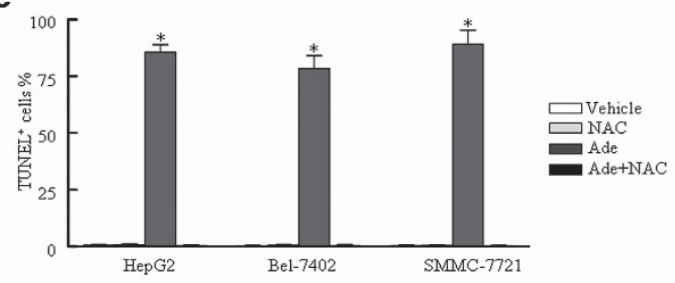

f

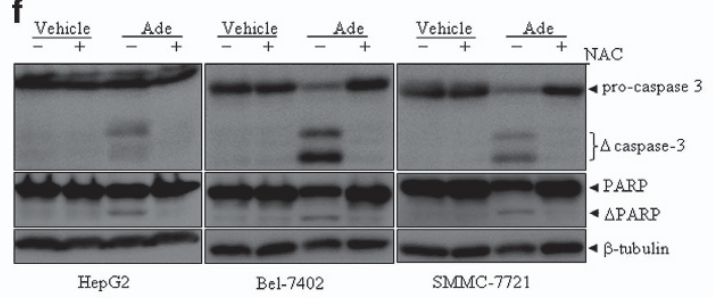


in siPrx I\#2-expressing SMMC-7721 and Bel-7402 cells. Of note, C173S-Prx I overexpression potentiated adenanthininduced cell death (Figures $5 \mathrm{c}$ and $\mathrm{d}$ ). In addition, reexpression of WT-Prx II but not C172S-Prx II could rescue adenanthin-induced cell death in siPrx II-expressing SMMC7721 and Bel-7402 cells (Figures $5 e$ and f). Taken together, these results further confirm that Prx I and Prx II directly contribute to adenanthin-induced cytotoxicity of HCC cells.

Adenanthin exhibits significant therapeutic activity in HCC xenografts. Finally, we subcutaneously injected
SMMC-7721 cells into BALB/c nude mice. Two weeks later, these mice were intraperitoneally injected with adenanthin (10 or $20 \mathrm{mg} / \mathrm{kg}$ ) or saline as control by the protocol described in materials and methods. Administration of adenanthin at $10 \mathrm{mg} / \mathrm{kg}$ did not present observable toxic effects on mice, but $20 \mathrm{mg} / \mathrm{kg}$ adenanthin decreased body weight of mice compared with the control and $10 \mathrm{mg} / \mathrm{kg}$ adenanthin-treated mice (Figure 6a). At the end of therapy, autopsies showed that adenanthin-treated mice had much smaller tumor masses (Figure $6 \mathrm{~b}$ ). The tumor volumes and average tumor weights with the treatment of adenanthin of 10

a
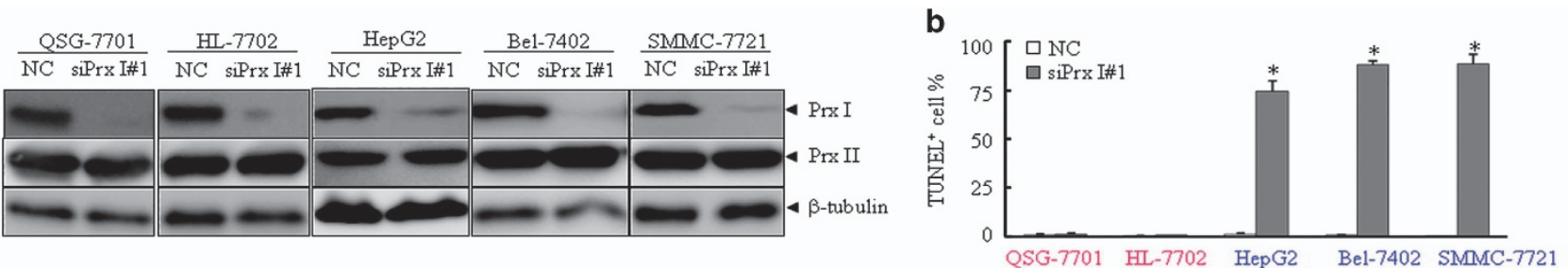

C

d
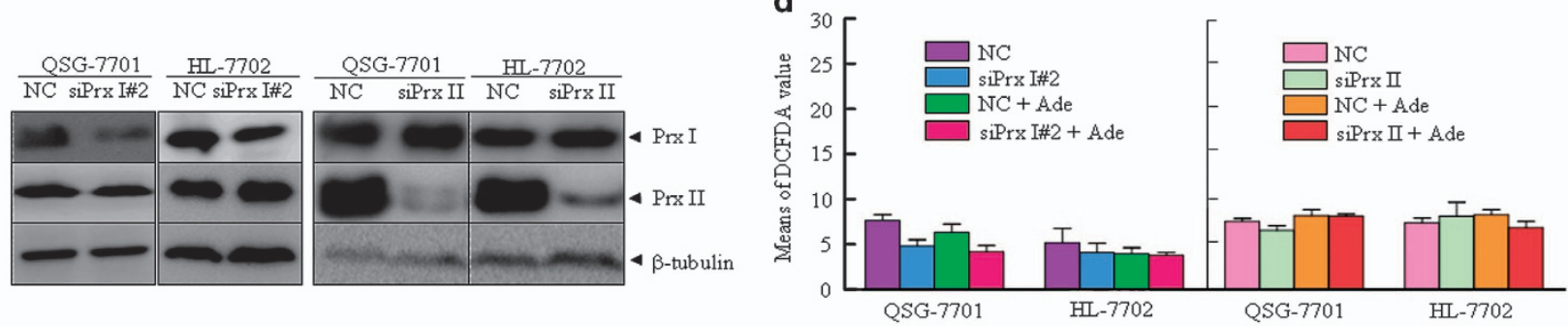

e
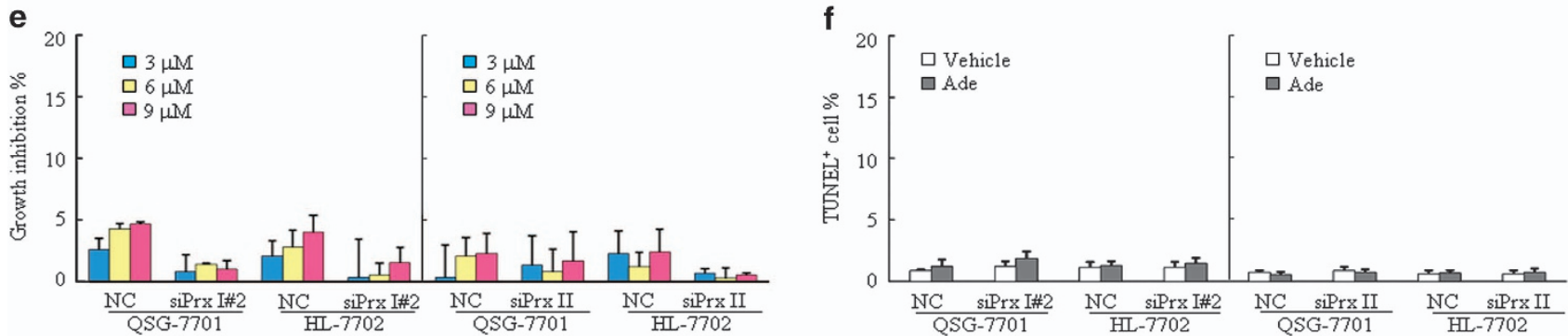

Figure 3 The effects of Prx I or Prx II silencing and/or adenanthin on human hepatic and HCC cells. (a, b) The cells were infected with EGFP-tagged siPrx I\#1 for 2 days, followed by sorting for EGFP-positive cells. Prx I and Prx II proteins were examined by western blots with $\beta$-tubulin as a loading control (a). TUNEL ${ }^{+}$cells $\%$ (b) were observed and analyzed when the sorted cells were cultured for 4 (for HepG2) or 6 days (for other cells). The symbol ${ }^{*}$ indicates $P<0.01$ compared with NC siRNA-expressing cells. (c-f) Two human immortal hepatic cell lines were stably infected with siPrx I\#2 or siPrx II, together with NC as controls. Prx I and Prx II proteins were examined by western blots with $\beta$-tubulin as a loading control(c). Fluorescent intensities of DCFDA staining were quantified on flow cytometry for the cells treated with and without adenanthin at $9 \mu \mathrm{M}$ for $1 \mathrm{~h}$. Data represent means with bar as S.D. of triplicate samples in an independent experiment (d). These siRNA-infected cells were treated with and without indicated concentrations (e) or $9 \mu \mathrm{M}$ adenanthin (f) for $24 \mathrm{~h}$, followed by CCK-8 (e) and TUNEL assays (f). All experiments were repeated three times with the same results

Figure 2 The role of ROS in adenanthin-induced cell death of HCC cells. (a, b) After pretreatment with and without $2 \mathrm{mM} \mathrm{NAC} \mathrm{for} 4 \mathrm{~h}$, cells were treated with or without adenanthin at $3 \mu \mathrm{M}$ (for HepG2) or $9 \mu \mathrm{M}$ (for the other cells) for $1 \mathrm{~h}$. Then, fluorescent intensity of DCFDA staining was analyzed on flow cytometry (a) and quantified data were shown (b). Data represent means with bar as S.D. of triplicate samples in an independent experiment. The symbols * and \# stand for $P<0.01$ compared, respectively, with the vehicle- and adenanthin-treated cells. (c) Cell lysates of HL-7702 and SMMC-7721 cells with treatment as performed in panel (a) were probed with DCP-Bio1, followed by western blot with streptavidin. Coomassie blue staining was used as protein loading control. Null indicates the cell lysates without probe incubation. (d-f) After pretreatment with and without $2 \mathrm{mM} \mathrm{NAC}$ for $4 \mathrm{~h}$, three HCC cells were incubated with and without adenanthin at 3 (for HepG2) or $9 \mu \mathrm{M}$ (for other two cells) for $48 \mathrm{~h}$, followed by morphological observation (d), TUNEL assay (e) and western blots for the indicated proteins (f). The scale bars in panel (d) are $100 \mu \mathrm{m}$. In panel (e), the symbol * presents $P<0.01$ compared with the vehicle-treated cells. All experiments were repeated three times with the same results. $(\mathrm{g})$ After pretreatment with and without $2 \mathrm{mM}$ NAC, $1 \mathrm{mM}$ dithiothrietol, $5 \mathrm{mM}$ glutathione, $1 \mathrm{mM}$ tiron or $2 \mathrm{mM}$ tempol for $4 \mathrm{~h}$, the cells as indicated were treated with or without adenanthin at 3 (for HepG2) or $9 \mu \mathrm{M}$ (for SMMC-7721 and Bel-7402) for 1 (upper part) or $48 \mathrm{~h}$ (lower part). The fluorescent intensity of DCFDA staining were analyzed and quantified on flow cytometry (upper part) and TUNEL-positive cells $\%$ was calculated (lower part). All data represent means with bar as S.D. of triplicate samples in an independent experiment. The symbol ${ }^{*}$ stands for $P<0.01$ compared with the adenanthin alone-treated cells 
a

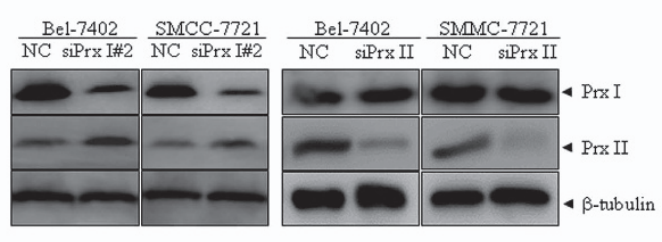

C

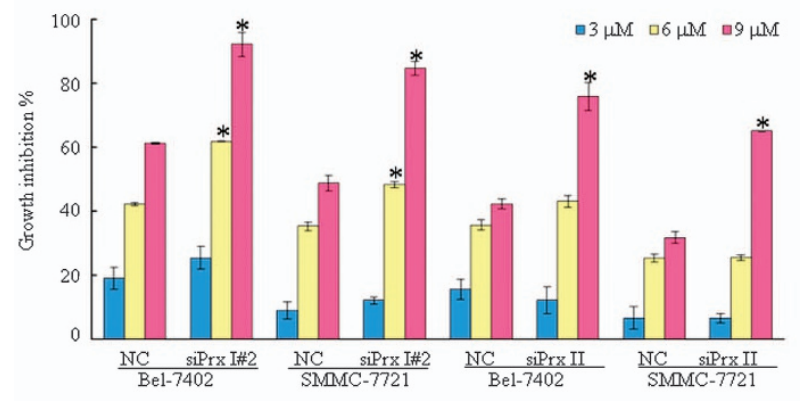

e

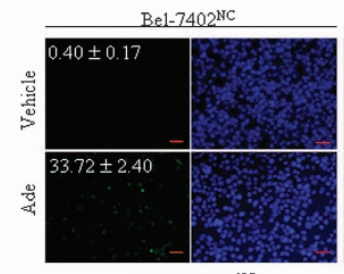

SMMC-7721

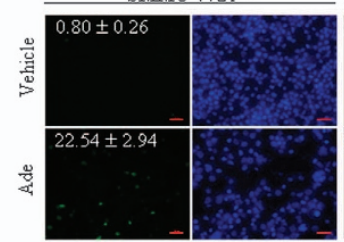

Bel-7402:iPxx IR
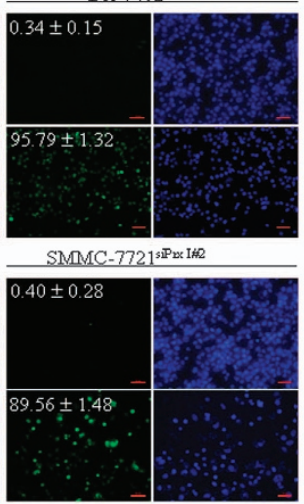

SMMC-7721: 1 Px: I I $\mathbf{b}_{300}$

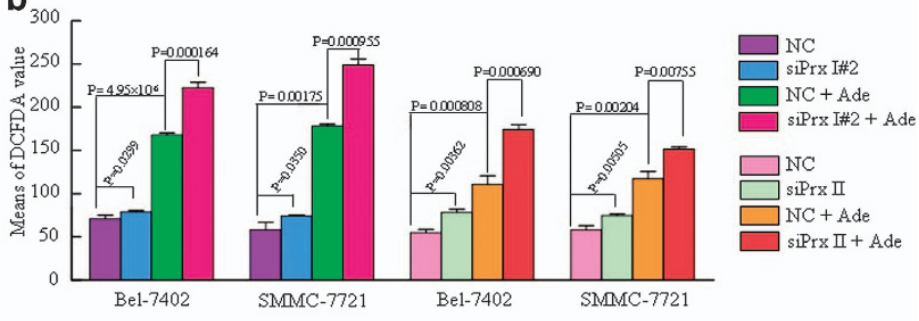

d

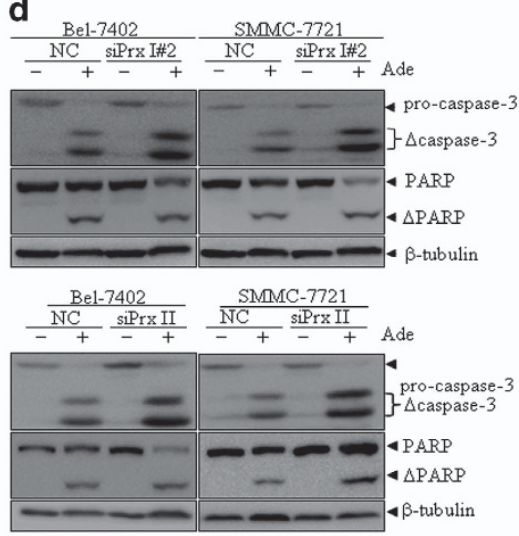

f

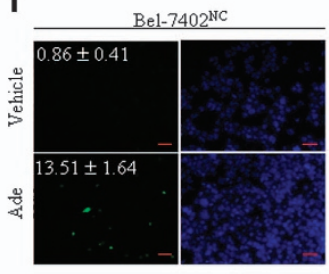

SMMC- $7721^{\mathrm{NC}}$

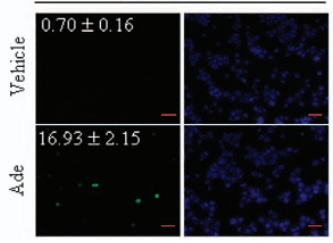

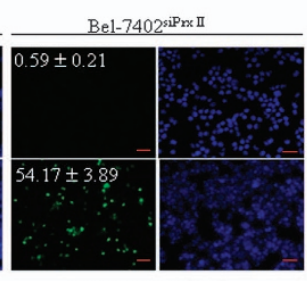

SMMC- $7721^{s \mathbb{P} x x}$ II

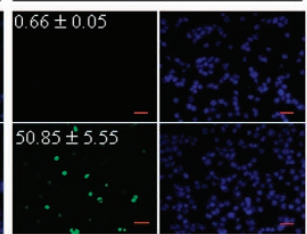

Figure 4 The effects of adenanthin on ROS accumulation and cell death of HCC cells in the presence of Prx I and Prx II knockdown. (a) Bel-7402 and SMMC-7721 cells were stably infected with siPrx I\#2 or siPrx II together with NC and Prx I or Prx II protein was blotted with $\beta$-tubulin as a loading control. (b) These siRNA-infected cells were treated with or without adenanthin at $9 \mu \mathrm{M}$ for $1 \mathrm{~h}$, and then fluorescent intensities of DCFDA staining were quantified on flow cytometry. Data represent means with bar as S.D. of triplicate samples in an independent experiment. (c) These siRNA-expressing cells were treated with and without adenanthin at concentrations as indicated for $24 \mathrm{~h}$, followed by CCK- 8 assay. The symbol ${ }^{*}$ indicates $P<0.01$ compared with NC-infected cells with the corresponding treatments. (d-f) These siRNA-infected cells were treated with and without $9 \mu \mathrm{M}$ adenanthin for $24 \mathrm{~h}$, followed by western blots for the indicated proteins (d) and TUNEL assay (e and f). The scale bars in panel (e) and (f) are $50 \mu \mathrm{m}$. All experiments were repeated three times with the same results

and $20 \mathrm{mg} / \mathrm{kg}$ group were significantly decreased in comparison with control mice, although 10 and $20 \mathrm{mg} / \mathrm{kg}$ of adenanthin appeared to present the similar therapeutic activity (Figures 6c and d).

\section{Discussion}

Ent-kauranes are the largest and widely distributed group of the known Isodon diterpenoids, and have recently been shown as therapeutic agents against bacterial infection, tumor, inflammation and feeding. ${ }^{31}$ Here, we report that a natural diterpenoid designated as adenanthin can induce cell death of HCC cells more effectively than that of two human immortal hepatic cell lines. Accordingly, the agent can also significantly inhibit the growth of xenografts of HCC cells without significant toxic effects.

ROS, such as $\mathrm{H}_{2} \mathrm{O}_{2}$, arise during normal aerobic metabolism. They are constantly generated during electron transfer in the respiratory chain, in peroxisomes, and as products of a growing list of NADPH oxidases. ${ }^{4,32}$ The increase in ROS generation is one common biochemical change in cancer cells. Conventionally, increased ROS in cancer cells is considered as an adverse factor, because ROS increase appears to play an important role in maintaining cancer phenotype because of their stimulating effects on cancer cell proliferation, genetic instability and senescence 
a

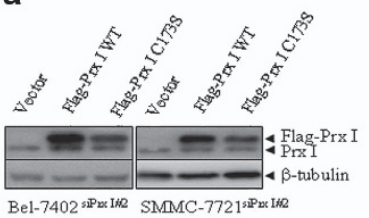

C

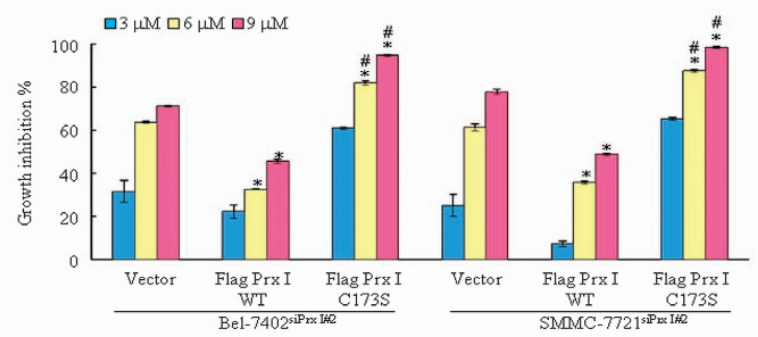

Vehicle
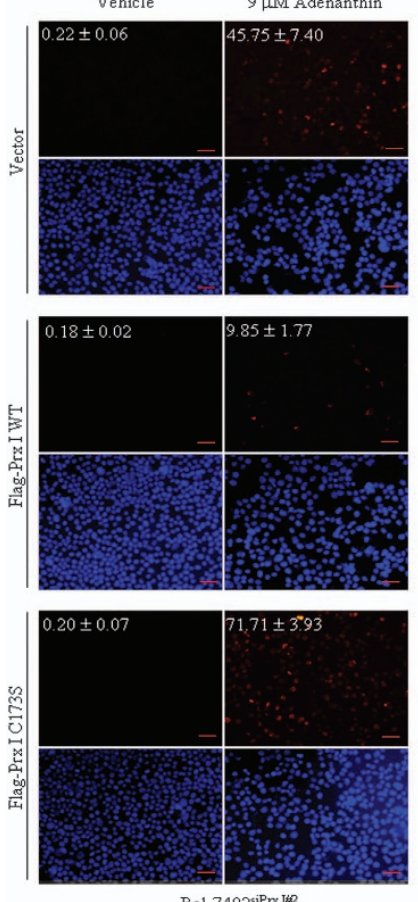

Bel-7402 $2^{\text {sipx }}$ I
Vehicle
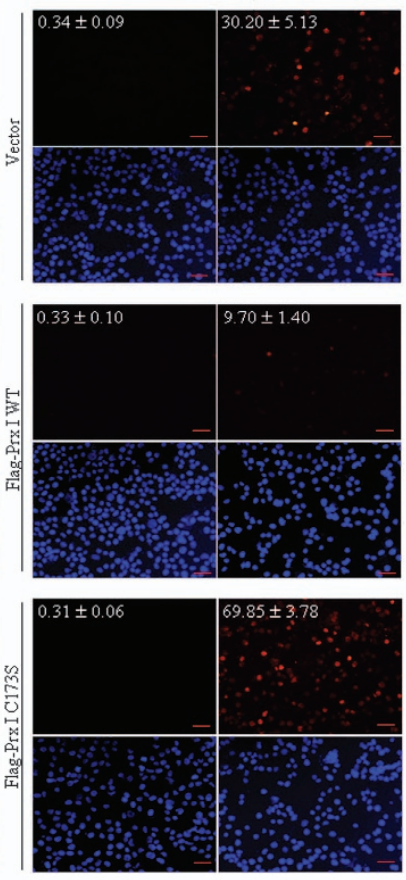

SMMC-7721 1 SPrx If b

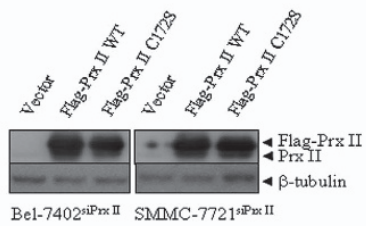

e

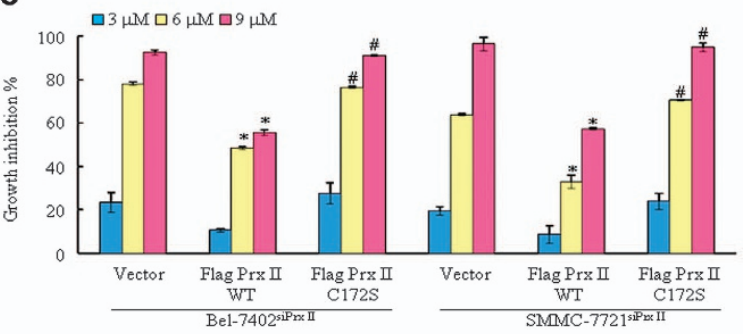

f Vehicle $9 \mu \mathrm{M}$ Adenanthin

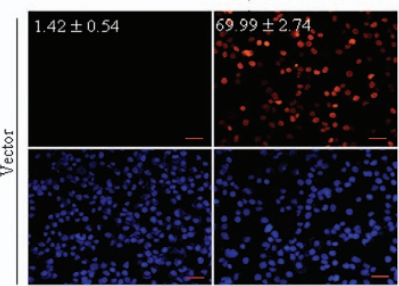

Vehicle
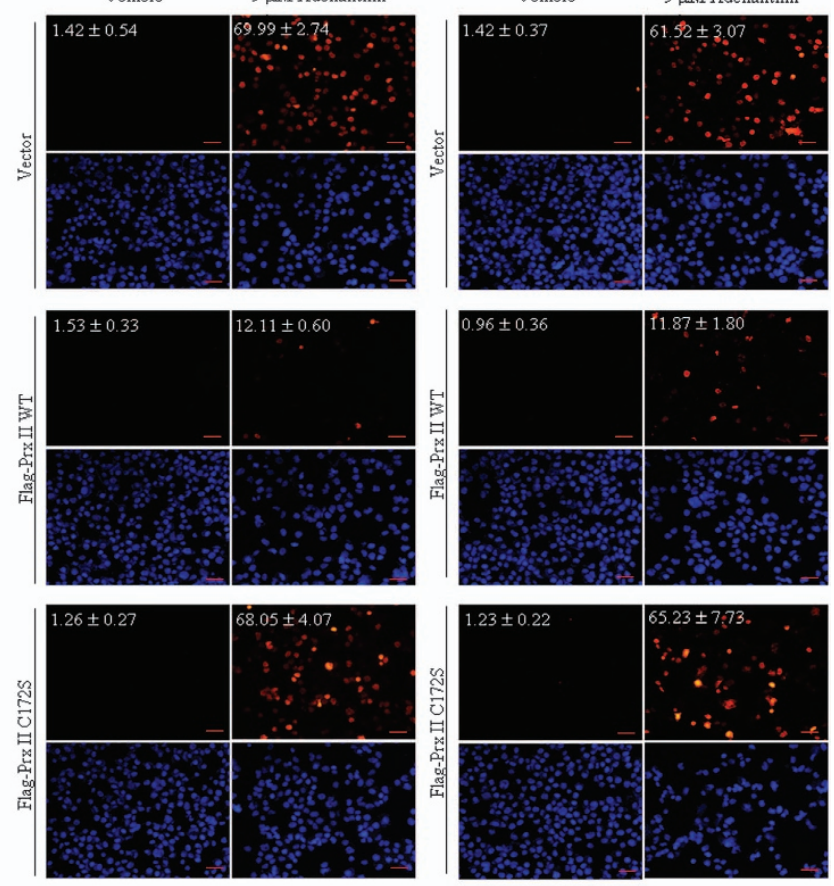

Bel-7402 2 ip $x$ II

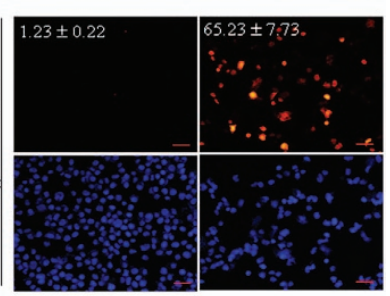

SMMC-7721 $1^{\text {sipex II }}$

Figure 5 The effects of ectopic expression of wild-type or mutated Prx I/II on adenanthin-enhanced cytotoxic effects on Prxs-silenced HCC cells. (a, b) Bel-7402 and SMMC-7721 cells stably expressing siPrx II2 (a) or siPrx II (b), which silenced Prx I or Prx II expression as shown in Figure 4a, were stably transfected with wild-type (WT) Prx $\mathrm{I} / \mathrm{II}$ and their mutants, followed by western blots for Prx I and Prx II proteins with $\beta$-tubulin as a loading control. (c, e) These cells were, respectively, treated with and without the indicated concentrations of adenanthin for $24 \mathrm{~h}$, followed by CCK-8 assay. (d, f) The indicated cells were treated with and without $9 \mu \mathrm{M}$ adenanthin for $18 \mathrm{~h}$. TUNEL ${ }^{+}$cells were observed and analyzed. The values represent the means \pm S.D. of TUNEL ${ }^{+}$cells $\%$. The scale bars in panels (d) and (f) are $50 \mu \mathrm{m}$. The symbols * and ${ }^{\#}$ in panels (c) and (e) indicate $P<0.01$ compared, respectively, with empty vector- and Flag-tagged WT Prx I/II-expressing cells with the corresponding treatments

evasion. ${ }^{33,34}$ However, increasing lines of evidence show that the excessive levels of ROS stress may be beneficial to the clearance of cancer cells, in which cells are likely to be more vulnerable to damage when further ROS insults are induced by exogenous agents. ${ }^{35,36}$ Therefore, manipulating ROS levels by redox modulation would become an ideal way to the prevention and treatment of cancers. ${ }^{37}$ On the basis of these notions, we show that adenanthin moderately increases ROS accumulation in HCC cell lines, which exhibit a significantly higher basal ROS level than human hepatic cells. On the other hand, all three thiol and non-thiol antioxidants significantly block death-inducing activity of adenanthin. These data support that adenanthin kills HCC cells through the increased ROS, which is reminiscent of piperlongumine and $\beta$-phenylethyl isothiocyanate. These two small molecules were reported to selectively kill cancer cells through ROSmediating mechanisms. ${ }^{35,36}$

Accumulating evidence showed that Prxs protect cells and tissues from oxidative damage through their peroxidase activities. Prx I and II have also been found to have antiapoptotic functions through direct or indirect interactions with the key cell death regulators, such as apoptosis signal 
a

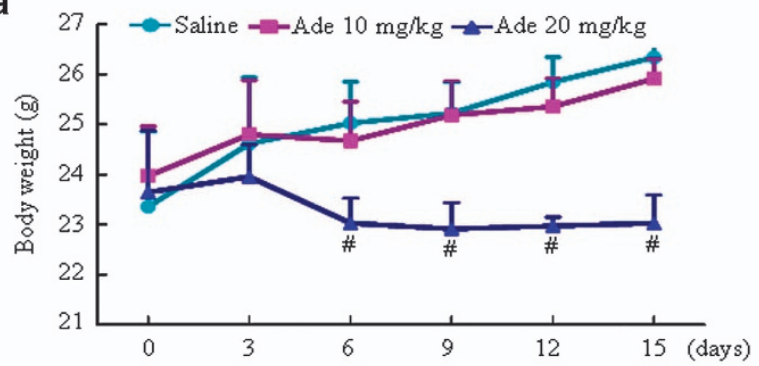

C

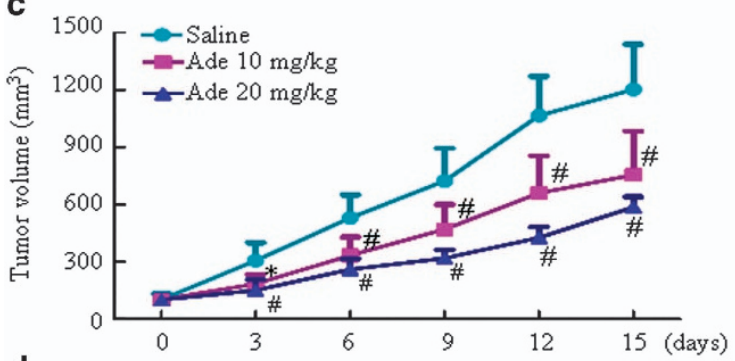

d

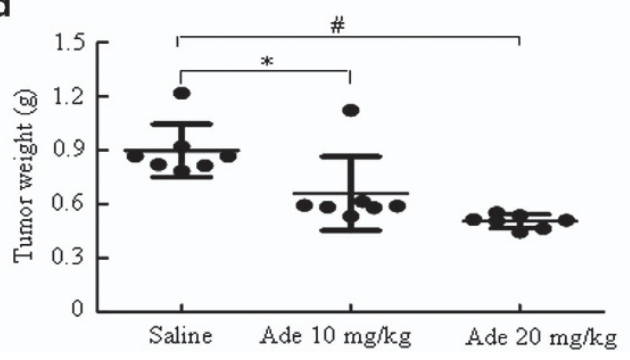

b

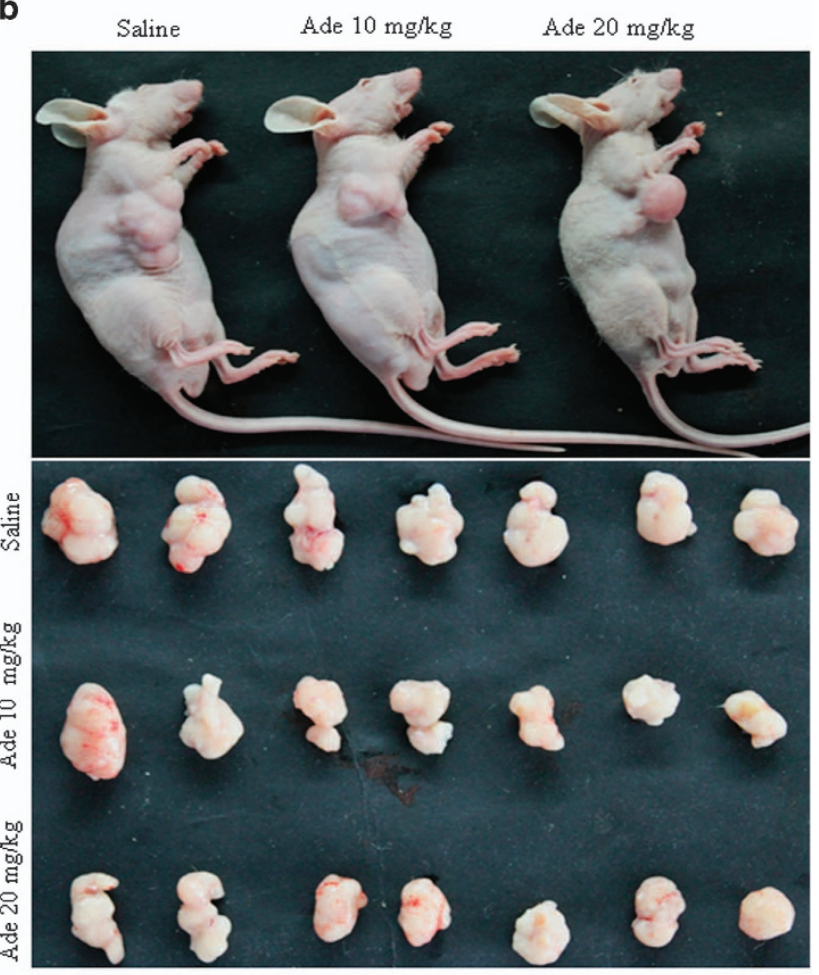

Figure 6 The in vivo effect of adenanthin in HCC xenograft model. SMMC-7721 cells were transplanted into the right sides of nude mice for 2 weeks. Then mice were intraperitoneally injected with adenanthin at the indicated doses for continuous four courses. Each course included continuous 3 days' injection and one day's break. (a) The mice weights were measured every 3 days following adenanthin treatment. The data indicate means with bar as S.D. for seven mice in each group. (b) The representative animals with tumor burden and the tumor masses were photographed at the end of treatment (day 15). (c) The tumor volumes were measured as performed in panel (a). The data indicate means with bar as S.D. for seven mice in each group. (d) Weights of tumors in each mice were dotted, in which middle horizontal line represent the mean with bar as S.D. of seven mice in each treatment. The symbols ${ }^{*}$ and ${ }^{\#}$ indicate respectively $P<0.05$ and 0.01 compared with the saline-injected mice

regulating kinase 1 (ASK1), p66 ${ }^{\text {Shc }}$, JNK and c-Abl, ${ }^{7,38,39}$ and other signaling molecules involved in ROS-induced cell death include MAPK (p38, JNK and ERK), NF-kB, AKT, AMPK1 and Bax/Bcl2 family. ${ }^{40}$ Previously, we reported that adenanthin can target to and inhibit peroxidase activities of Prx I and Prx II. ${ }^{21,22}$ Therefore, we asked whether adenanthin increases ROS production in HCC cells through targeting Prx I and Prx II. Although several lines of evidence demonstrated that the expressions of Prx I and Prx II were higher in HCC tissues compared with those in adjacent non-tumorous liver tissues or pre-HCC tissues, ${ }^{41-43}$ here we found that all three HCC and two human immortal hepatic cell lines have the similar Prx I or Prx II levels. Even so, HCC cells are more sensitive to adenanthin than human immortal hepatic cells, suggesting that Prx I/II exert a critical function for survival of HCC but not other two immortal hepatic cells. Indeed, we show that Prx I is necessary for the survival of HCC, because the siRNAmediated complete suppression of Prx I expression can directly trigger HCC cells to undergo death. Hence, we used adenanthin to treat HCC and immortal hepatic cells with the partial suppression of Prx I and great inhibition of Prx II, under which all cells can survive. Our results show that the suppression of Prx I or Prx II expression significantly enhances
ROS-accumulating and killing effects of adenanthin on HCC cells, which can be abrogated by the ectopic expressions of Prx I and Prx II but not their mutants with adenanthin-bound sites. It should be pointed out that partial decrease of Prx I protein by siPrx I\#2 did not elevate ROS levels substantially, whereas adenanthin elevated ROS to two to three folds, suggesting that adenanthin might elevate ROS by mechanisms beyond modulation of Prx I, which remains to be further explored. Actually, a recent report showed that adenanthin can also bind with thioredoxin-1 (Trx-1) and inhibits the activity of Trxthioredoxin reductase system and protein disulfide isomerase in vitro and in cultured cells. ${ }^{30}$ Additionally, adenanthin was also reported to inhibit NF- $\kappa B$ signaling in experimental autoimmune encephalomyelitis. ${ }^{44}$ Therefore, we also evaluated whether $\mathrm{NF}-\kappa \mathrm{B}$ signaling is involved in adenanthin-induced HCC cell death. The results showed that the overexpression of $p 65$, one subunit of NF- $k B$, did not affect adenanthin-induced death of three HCC cells (data not shown).

Collectively, our findings propose that Prx I and II mediate the death-inducing selectivity of adenanthin on HCC, and adenanthin can serve as the natural lead compound for the development of Prx I- and Prx II-targeted selective therapeutic agents for HCC patients. 
Materials and Methods

Cell lines and reagents. All cell lines were obtained from cell resource center of Shanghai Institutes for Biological Sciences, Chinese Academy Science, Shanghai, China. Human normal liver cell lines, QSG-7701 and HL-7702, were cultured in RPMI-1640 medium (SH30027.01, HyClone, Logan, UT, USA), supplemented with $10 \%$ fetal bovine serum (26140, Gibco, Grand Island, NY USA); human HCC cells including SMMC-7721, Bel-7402 and HepG2, and human embryonic kidney cells HEK293T were cultured in Dulbecco's modified Eagle's medium (SH30022.01B, HyClone) with 10\% fetal bovine serum. These cells were incubated in a $5 \% \mathrm{CO}_{2} / 95 \%$ air-humidified atmosphere at $37^{\circ} \mathrm{C}$. Adenanthin was isolated from the dried aerial parts of the leaves of $R$. adenantha. Adenanthin and VP16 (341205, Merck-Millipore, Boston, MA, USA) were dissolved in DMSO (Sigma-Aldrich, St. Louis, MO, USA) as $40 \mathrm{mM}$ and $100 \mathrm{mM}$ stock solution, respectively. Tiron (172553), tempol (176141), NAC (A8199), dithiothrietol (D0632) and glutathione (G6529) were purchased from Sigma-Aldrich.

Cell viability assay and IC50 values. About 8000 cells per well were seeded into 96-well plates. After $12 \mathrm{~h}$ incubation, cells were treated with vehicle control or various concentrations of adenanthin for $48 \mathrm{~h}$. Then, CCK-8 (CKO4 Dojindo Molecular Technologies, Kumamoto, Japan) was added into each well and incubated at $37^{\circ} \mathrm{C}$ for $2 \mathrm{~h}$. The absorbance was measured by a Synergy $\mathrm{H} 4$ Hybrid Reader (BioTek Instruments, Inc., Winooski, VT, USA) at a wavelength of $450 \mathrm{~nm}$. Relative growth inhibition was calculated and IC50 were analyzed by Graph Prism 5 (La Jolla, CA, USA).

TUNEL assay. Cells were collected onto slides and fixed with $4 \%$ paraformaldehyde for $15 \mathrm{~min}$. After permeabilization by ice-cold methanol for $15 \mathrm{~min}$, the cells were incubated with TUNEL-FITC/TMR (11684795910/ 12156792910, Roche, Basel, Switzerland) reaction buffer for $2 \mathrm{~h}$ at $37^{\circ} \mathrm{C}$. Cellular DNA were counterstained with 4',6-diamidino-2-phenylindole (D9564, Sigma, St. Louis, MO, USA). Fluorescence signals were captured on a Nikon Eclipse Ti microscope (Nikon, Tokyo, Japan) and images were analyzed by Image Pro Plus 6.0 software (Media Cybernetics, Silver Spring, MD, USA).

Detection of ROS by flow cytometry. Cells were washed with phosphate-buffered saline and then re-suspended in pre-warmed phosphatebuffered saline $\left(37^{\circ} \mathrm{C}\right)$, followed by incubation with $10 \mu \mathrm{M}$ 5-(and 6)-chloromethyl2',7'-dichlorodihydrofluorescein diacetate, acetyl ester (C-6827, CM-H2-DCFDA, Invitrogen, Carlsbad, CA, USA) for $30 \mathrm{~min}$ at $37^{\circ} \mathrm{C}$. Next, the cells were washed with phosphate-buffered saline twice and scraped into $0.3 \mathrm{ml}$ of ice-cold phosphate-buffered saline. CM-H2-DCFDA fluorescence was determined by measuring 10000 events per sample following excitation with a $488 \mathrm{~nm}$ wavelength laser and reading through a 530/30 filter (FACSCalibur, BD Bioscience, San Jose, CA, USA).

Capture of DCP-Bio1-labeled proteins. SMMC-7721 and HL-7702 cells were stimulated with $9 \mu \mathrm{M}$ adenanthin at $37^{\circ} \mathrm{C}$ for $1 \mathrm{~h}$. Cells $\left(1 \times 10^{6}\right)$ were collected and quenched with $500 \mu$ lysis buffer $(50 \mathrm{mM}$ Tris- $\mathrm{HCl}, 100 \mathrm{mM} \mathrm{NaCl}$, $0.1 \%$ SDS, $0.5 \%$ sodium deoxycholate, $0.5 \%$ NP $40,0.5 \%$ Triton $\mathrm{X}-100,1 \mathrm{mM}$ EDTA, $1 \mathrm{mM}$ EGTA, $50 \mathrm{mM} \mathrm{NaF}, 10 \mathrm{mM}$ IAA, $20 \mathrm{mM} \beta$-mercaptoethanol, $1 \mathrm{mM}$ Na3VO4, $10 \mathrm{mM}$ NEM, $100 \mu \mathrm{M}$ DTPA and $200 \mathrm{U} / \mathrm{ml}$ catalase). The cell lysate was incubated on ice for $1 \mathrm{~h}$, and then sonicated and centrifuged. DCP-Bio $1(100 \mu \mathrm{M}$; EE0021, KeraFAST, Boston, MA, USA) were added into supernatant from the cell lysates. After $1 \mathrm{~h}$ incubation, the samples were collected for western blot.

Plasmids and transfection. Human Prx I and Prx II cDNAs were amplified from HEK293T cells by reverse transcription-PCR, and then cloned into pLVXIRES-ZsGreen vector (PT4064-5, Clontech, Palo Alto, CA, USA) for generating Prx I and Prx II expression plasmids. SiRNA-resistant wide-type and cysteinemutated Prx I/II (C173S and C172S) plasmids were generated by QuickChange Lightning Site-Directed Mutagenesis Kit (210518, Stratagen, La Jolla, CA, USA). The plasmids we made were further confirmed by DNA sequencing (Biosune, Shanghai, China). Transient transfection was performed with Hilymax transfection reagents according to the manufacturer's instructions (H357, Dojindo Molecular Technologies).

siRNA design and viral infection. Complementary oligonucleotides specifically against Prx I or Prx II (siPrx I\#1, siPrx I\#2 and siPrx II) were synthesized, annealed and ligated into PSIREN-RetroQ vector according to the manufacturer's instruction (631526, Clontech). The target sequences for Prx I and Prx II were shown, respectively, as following: $5^{\prime}$-AGATATCAGCCTGTCTGAC-3' for siPrx I\#1, 5'-CTGCCAAGTGATTGGTGCT-3' for siPrx I\#2, 5'-TATTTCTCCAA ACACAATT-3' for siPrx II and 5'-TCCCGTGAATTGGAATCCTNC-3' for NC siRNA. These siRNA or NC plasmids (pSIREN-RetroQ or pLSLG-EGFP) were cotransfected with packaging plasmids including pCMV-Gag pol, VSV-Gor pMD.G and $\Delta 8.91$ into 293T cells to produce retrovirus or lentivirus. After transfection for 48 or $60 \mathrm{~h}$, the viral supernatants were collected, filter-sterilized, and, respectively, added into two human liver cells and three HCC cells $\left(1 \times 10^{6}\right.$ cells/dish) within $10 \mathrm{~cm}$ dishes with the medium containing $1 \mu \mathrm{g} / \mathrm{ml}$ of polybrene. Stably transfected cells were selected by $1 \mu \mathrm{g} / \mathrm{ml}$ puromycin or FACS sorting after viral infection for $48 \mathrm{~h}$.

Western blot. The whole cell lysates were extracted in $1 \times$ SDS, equally loaded on $10-15 \%$ SDS-polyacrylamide gels, and subsequently transferred to nitrocellulose membrane (162-0115, Bio-Rad, Berkeley, CA, USA) and stained with $0.4 \%$ Ponceau $S$ red to ensure equal protein loading. After blocking with $5 \%$ non-fat milk in TBST for $1 \mathrm{~h}$ at room temperature, the membranes were incubated at $4{ }^{\circ} \mathrm{C}$ overnight with various specific primary antibodies, and followed by incubation for $2 \mathrm{~h}$ at room temperature with appropriate horseradish peroxidaselinked secondary antibodies (7074, Cell Signaling, Millipore, Billerica, MA, USA). The signals were detected by chemiluminescence phototope-HRP kit (WBKLS0500, Millipore) according to manufacturer's instructions. Polyclonal anti-Prx I (sc-7381) and anti-PARP (sc-8007) antibodies were purchased from Santa Cruz Biotechnology (Dallas, TX, USA). Antibodies against caspase-9 (9502), caspase-3 (9662), and biotin (5597) were purchased from Cell Signaling. Anti-Prx II (3539) was from Epitomics (Burlingame, CA, USA).

Animal experiments. Four-week-old male BALB/c nude mice were obtained from Shanghai laboratory of animal research center, Shanghai, China. SMMC7721 cells $\left(3 \times 10^{6}\right)$ were subcutaneously injected in one side of ventral flanks. When tumor volumes reached to $100 \mathrm{~mm}^{3}$, the mice with tumor burden were randomly grouped and injected intraperitoneally with adenanthin $(10 \mathrm{mg} / \mathrm{kg}$ and $20 \mathrm{mg} / \mathrm{kg}$ ) or saline (injection daily for 3 days and resting 1 day). The total treatment period is 15 days. Tumor growth was monitored by caliper rule every 3 days. ${ }^{45}$ At the end of adenanthin treatment, mice were killed and tumors were picked, photographed, size measured and weighed. All animals were handled in strict accordance to the 'Guide for the Care and Use of Laboratory Animals' and the 'Principles for the Utilization and Care of Vertebrate Animals', and all animal work was approved by the Institutional Animal Care and Use Committee at the Shanghai Institutes for Biological Sciences, Chinese Academy of Sciences and Shanghai Jiao Tong University School of Medicine.

Statistical analysis. Student's t-test was used to evaluate differences between two groups. A $P$-value of less than 0.05 or 0.01 was considered statistically significant.

\section{Conflict of interest}

The authors declare no conflict of interest.

Acknowledgements. Grant supports: This work is supported in part by grants from National Natural Science Foundation of China (91213304; 81372191; 81230048), Shanghai Science and Technology Committee (11JC1406800), and Shanghai Committee of Education.

1. Wood ZA, Poole LB, Karplus PA. Peroxiredoxin evolution and the regulation of hydrogen peroxide signaling. Science 2003; 300: 650-653

2. Rhee SG, Woo HA. Multiple functions of peroxiredoxins: peroxidases, sensors and regulators of the intracellular messenger $\mathrm{H}_{2} \mathrm{O}_{2}$, and protein chaperones. Antioxid Redox Signal 2011; 15: 781-794.

3. Rhee SG. Cell signaling. $\mathrm{H}_{2} \mathrm{O}_{2}$, a necessary evil for cell signaling. Science 2006; 312 : 1882-1883

4. Dickinson BC, Chang CJ. Chemistry and biology of reactive oxygen species in signaling or stress responses. Nat Chem Biol 2011; 7: 504-511.

5. Rhee SG, Chae HZ, Kim K. Peroxiredoxins: a historical overview and speculative preview of novel mechanisms and emerging concepts in cell signaling. Free Radic Biol Med 2005; 38: $1543-1552$. 
6. Hall A, Karplus PA, Poole LB. Typical 2-Cys peroxiredoxins-structures, mechanisms and functions. FEBS J 2009; 276: 2469-2477.

7. Nystrom T, Yang J, Molin M. Peroxiredoxins, gerontogenes linking aging to genome instability and cancer. Genes Dev 2012; 26: 2001-2008.

8. Cao J, Schulte J, Knight A, Leslie NR, Zagozdzon A, Bronson R et al. Prdx1 inhibits tumorigenesis via regulating PTEN/AKT activity. EMBO J 2009; 28: 1505-1517.

9. Egler RA, Fernandes E, Rothermund K, Sereika S, de Souza-Pinto N, Jaruga P et al. Regulation of reactive oxygen species, DNA damage, and c-Myc function by peroxiredoxin 1. Oncogene 2005; $24: 8038-8050$.

10. Neumann CA, Krause DS, Carman CV, Das S, Dubey DP, Abraham JL et al. Essential role for the peroxiredoxin Prdx1 in erythrocyte antioxidant defence and tumour suppression. Nature 2003; 424: 561-565.

11. Zhang B, Wang $Y$, Su Y. Peroxiredoxins a novel target in cancer radiotherapy. Cancer Lett 2009; 286: 154-160.

12. Kang SW, Rhee SG, Chang TS, Jeong W, Choi MH. 2-Cys peroxiredoxin function in intracellular signal transduction: therapeutic implications. Trends Mol Med 2005; 11: 571-578.

13. El-Serag HB, Rudolph KL. Hepatocellular carcinoma: epidemiology and molecular carcinogenesis. Gastroenterology 2007; 132: 2557-2576.

14. Forner A, Llovet JM, Bruix J. Hepatocellular carcinoma. Lancet 2012; 379: 1245-1255.

15. de Lope CR, Tremosini S, Forner A, Reig M, Bruix J. Management of HCC. J Hepatol 2012; 56(Suppl 1): S75-S87.

16. Li J, Xu Y, Long XD, Wang W, Jiao HK, Mei Z et al. Cbx4 governs HIF-1alpha to potentiate angiogenesis of hepatocellular carcinoma by its SUMO E3 ligase activity. Cancer Cell 2014; 25: 118-131.

17. Feng GS. Conflicting roles of molecules in hepatocarcinogenesis: paradigm or paradox. Cancer Cell 2012; 21: 150-154.

18. Wang K. Molecular mechanisms of hepatic apoptosis. Cell Death Dis 2014; 5: e996.

19. Mei Z, Jiao H, Wang W, Li J, Chen G, Xu Y. Polycomb chromobox 4 enhances migration and pulmonary metastasis of hepatocellular carcinoma cell line MHCC97L. Sci China Life Sci 2014; 57: 610-617.

20. Lee JM, Han KH. Positioning and indication of sorafenib in the treatment algorithm and real practice setting: Western and eastern approach-Asian perspective. Oncology 2010; 78(Suppl 1): 167-171.

21. Liu CX, Yin QQ, Zhou HC, Wu YL, Pu JX, Xia L et al. Adenanthin targets peroxiredoxin I and II to induce differentiation of leukemic cells. Nat Chem Biol 2012; 8: 486-493.

22. Liu CX, Zhou HC, Yin QQ, Wu YL, Chen GQ. Targeting peroxiredoxins against leukemia. Exp Cell Res 2013; 319: 170-176.

23. Yap TA, Sandhu SK, Carden CP, de Bono JS. Poly(ADP-ribose) polymerase (PARP) inhibitors: Exploiting a synthetic lethal strategy in the clinic. CA Cancer J Clin 2011; 61: 31-49.

24. Luo J, Solimini NL, Elledge SJ. Principles of cancer therapy: oncogene and non-oncogene addiction. Cell 2009; 136: 823-837.

25. Wang J, Lin D, Peng H, Huang Y, Huang J, Gu J. Cancer-derived immunoglobulin G promotes tumor cell growth and proliferation through inducing production of reactive oxygen species. Cell Death Dis 2013; 4: e945.

26. Wani R, Qian J, Yin L, Bechtold E, King SB, Poole LB et al. Isoform-specific regulation of Akt by PDGF-induced reactive oxygen species. Proc Natl Acad Sci USA 2011; 108 : 10550-10555.

27. Shi Y, Nikulenkov F, Zawacka-Pankau J, Li H, Gabdoulline R, Xu J et al. ROS-dependent activation of JNK converts p53 into an efficient inhibitor of oncogenes leading to robust apoptosis. Cell Death Differ 2014; 21: 612-623.

28. Yang J, Su Y, Richmond A. Antioxidants tiron and N-acetyl-L-cysteine differentially mediate apoptosis in melanoma cells via a reactive oxygen species-independent NF-kappaB pathway. Free Radic Biol Med 2007; 42: 1369-1380.

29. Francischetti IM, Gordon E, Bizzarro B, Gera N, Andrade BB, Oliveira F et al. Tempol, an intracellular antioxidant, inhibits tissue factor expression, attenuates dendritic cell function, and is partially protective in a murine model of cerebral malaria. PLOS One 2014; 9: e87140.

30. Muchowicz A, Firczuk M, Chlebowska J, Nowis D, Stachura J, Barankiewicz J et al. Adenanthin targets proteins involved in the regulation of disulphide bonds. Biochem Pharmacol 2014; 89: 210-216.

31. Jiang B, Yang H, Li ML, Hou AJ, Han QB, Wang SJ et al. Diterpenoids from Isodon adenantha. J Nat Prod 2002; 65: 1111-1116.

32. Kumsta C, Jakob U. Redox-regulated chaperones. Biochemistry 2009; 48: 4666-4676.

33. Schumacker PT. Reactive oxygen species in cancer cells: live by the sword, die by the sword. Cancer Cell 2006; 10: 175-176.

34. Hanahan D, Weinberg RA. Hallmarks of cancer: the next generation. Cell 2011; 144: 646-674.

35. Raj L, Ide T, Gurkar AU, Foley M, Schenone M, Li X et al. Selective killing of cancer cells by a small molecule targeting the stress response to ROS. Nature 2011; 475 : 231-234.

36. Trachootham D, Zhou Y, Zhang H, Demizu Y, Chen Z, Pelicano H et al. Selective killing of oncogenically transformed cells through a ROS-mediated mechanism by beta-phenylethyl isothiocyanate. Cancer Cell 2006; 10: 241-252.

37. Trachootham D, Alexandre J, Huang P. Targeting cancer cells by ROS-mediated mechanisms: a radical therapeutic approach? Nat Rev Drug Discov 2009; 8: 579-591.

38. Shen HM, Liu ZG. JNK signaling pathway is a key modulator in cell death mediated by reactive oxygen and nitrogen species. Free Radic Biol Med 2006; 40: 928-939.

39. Ishii T, Warabi E, Yanagawa T. Novel roles of peroxiredoxins in inflammation, cancer and innate immunity. J Clin Biochem Nutr 2012; 50: 91-105.

40. Le Bras M, Clement MV, Pervaiz S, Brenner C. Reactive oxygen species and the mitochondrial signaling pathway of cell death. Histol Histopathol 2005; 20: 205-219.

41. Sun QK, Zhu JY, Wang W, Lv Y, Zhou HC, Yu JH et al. Diagnostic and prognostic significance of peroxiredoxin 1 expression in human hepatocellular carcinoma. Med Oncol 2014; 31: 786.

42. Yue HY, Cao J, Cui JF, Dai Z, Su JJ, Duan XX et al. [The expression of peroxiredoxin II in hepatocellular carcinoma and its significance]. Zhonghua Gan Zang Bing Za Zhi 2007; 15: 366-369.

43. Aguilar-Melero P, Prieto-Alamo MJ, Jurado J, Holmgren A, Pueyo C. Proteomics in HepG2 hepatocarcinoma cells with stably silenced expression of PRDX1. J Proteomics 2007; 79: 161-171.

44. Yin QQ, Liu CX, Wu YL, Wu SF, Wang Y, Zhang X et al. Preventive and therapeutic effects of adenanthin on experimental autoimmune encephalomyelitis by inhibiting NF-kappaB signaling. J Immunol 2013; 191: 2115-2125.

45. Jensen MM, Jorgensen JT, Binderup T, Kjaer A. Tumor volume in subcutaneous mouse xenografts measured by microCT is more accurate and reproducible than determined by 18F-FDG-microPET or external caliper. BMC Med Imaging 2008; 8: 16.

cc)(i) (2) $\odot$ Cell Death and Disease is an open-access journal published by Nature Publishing Group. This work is licensed under a Creative Commons Attribution-NonCommercialNoDerivs 3.0 Unported License. The images or other third party material in this article are included in the article's Creative Commons license, unless indicated otherwise in the credit line; if the material is not included under the Creative Commons license, users will need to obtain permission from the license holder to reproduce the material. To view a copy of this license, visit http://creativecommons.org/licenses/ by-nc-nd/3.0/ 